\title{
Etiologia e diagnóstico do sorriso gengival - Revisão de literatura
}

\author{
Etiology and diagnosis of gummy smile - Literature review \\ Etiología y diagnóstico de la sonrisa gingival - Revisión de la literatura
}

Laís Christina Pontes Espíndola ORCID: https://orcid.org/0000-0002-1023-7891 Universidade Federal de Alagoas, Brasil E-mail: laisespindola@ hotmail.com

Dyana dos Santos Fagundes ORCID: https://orcid.org/0000-0002-7427-4114 Universidade Federal de Alagoas, Brasil E-mail: dydyana_fagundes@hotmail.com

Vinícius Hallan Souza de Lima

ORCID: https://orcid.org/0000-0002-2711-744X Universidade Federal de Alagoas, Brasil E-mail: viniciushallan@hotmail.com

Thalwylla Reiler Morato dos Reis Moreira

ORCID: https://orcid.org/0000-0001-5632-2322 Universidade Federal de Alagoas, Brasil E-mail: thalwyllamorato@yahoo.com.br

\begin{abstract}
Resumo
Um sorriso representa, além de uma forma de comunicação, um meio de socialização. A simetria do sorriso consiste não apenas na harmonia entre forma, posição e cor dos dentes, mas também no equilíbrio entre face, lábios e tecido gengival. O "sorriso gengival" é caracterizado pela exposição gengival exagerada, resultando em um sorriso não estético. Esta condição pode surgir como resultado de um fator etiológico ou pela combinação de vários deles, como por exemplo alterações esqueléticas, dentárias, labiais, periodontais ou externas. É essencial que o cirurgião-dentista conheça seus fatores etiológicos para realizar um diagnóstico diferencial correto. O objetivo desse estudo é explorar o conceito, etiologia, classificação e diagnóstico do sorriso gengival, através de uma revisão de literatura. Foram realizadas buscas nas bases de dados Scientific Eletronic Library Online (SciELO), Biblioteca Virtual em Saúde (BVS), US National library of Medicine National Institutes of Health (PubMed) e Google Acadêmico. De acordo com os dados disponíveis na literatura, pode-se concluir que um diagnóstico correto é essencial para traçar um plano de tratamento individualizado, com resultados satisfatórios a longo prazo e que atendam a expectativas estéticas e funcionais do paciente, sendo assim o cirurgião-dentista deve estar apto a identificar as causas do sorriso gengival e definir o fator etiológico predominante em cada caso.
\end{abstract}

Palavras-chave: Estética dental; Sorriso; Gengiva.

\begin{abstract}
A smile represents, besides a form of communication, a means of socialization. The symmetry of a smile consists not only in the harmony between shape, position and color of teeth, but also in the balance between face, lips and gum tissue. The "gummy smile" is characterized by exaggerated gingival exposure, resulting in an un-aesthetic smile. This condition can arise as a result of one etiological factor, or by the combination of several of them, such as skeletal, dental, labial, periodontal or external alterations. It is essential that the dental surgeon knows its etiological factors in order to make a correct differential diagnosis. The objective of this study is to explore the concept, etiology, classification, and diagnosis of the gummy smile, through a literature review. Searches were performed in the Scientific Electronic Library Online (SciELO), Virtual Health Library (VHL), US National Library of Medicine National Institutes of Health (PubMed) and Google Scholar databases. According to the data available in the literature, it can be concluded that a correct diagnosis is essential to draw an individualized treatment plan, with satisfactory long-term results that meet the patient's aesthetic and functional expectations. Therefore, the dental surgeon should be able to identify the causes of gummy smile and define the predominant etiologic factor in each case.
\end{abstract}

Keywords: Dental aesthetics; Smile; Gingiva.

\section{Resumen}

La sonrisa representa, además de una forma de comunicación, un medio de socialización. La simetría de una sonrisa 
no sólo consiste en la armonía entre la forma, la posición y el color de los dientes, sino también en el equilibrio entre la cara, los labios y el tejido gingival. La "sonrisa gingival" se caracteriza por una exposición exagerada de las encías, lo que da lugar a una sonrisa poco estética. Esta condición puede surgir como resultado de un factor etiológico o de la combinación de varios de ellos, como alteraciones esqueléticas, dentales, labiales, periodontales o externas. Es fundamental que el cirujano dental conozca sus factores etiológicos para realizar un correcto diagnóstico diferencial. El objetivo de este estudio es explorar el concepto, la etiología, la clasificación y el diagnóstico de la sonrisa gingival mediante una revisión bibliográfica. Se realizaron búsquedas en las bases de datos Scientific Electronic Library Online (SciELO), Virtual Health Library (BVS), US National library of Medicine National Institutes of Health (PubMed) y Google Scholar. De acuerdo con los datos disponibles en la literatura, se puede concluir que un diagnóstico correcto es esencial para elaborar un plan de tratamiento individualizado, con resultados satisfactorios a largo plazo que cumplan con las expectativas estéticas y funcionales del paciente. Por lo tanto, el cirujano dental debe ser capaz de identificar las causas de la sonrisa gingival y definir el factor etiológico predominante en cada caso.

Palabras clave: Estética dental; Sonrisa; Encía.

\section{Introdução}

Um sorriso representa, além de uma forma de comunicação, um meio de socialização. Um sorriso harmônico é visto como um símbolo de beleza e bem estar na sociedade conteporânea. Ele pode expressar a sensação de alegria, sucesso, afeição, sensualidade, cortesia e demonstrar confiança e bondade (Oliveira, Molina, Furtado, Ghizoni, \& Pereira, 2013; Cairo, Graziani, Franchi, Defraia, \& Prato, 2012; Galdino et al., 2021).

Com o avanço das redes sociais e outras mídias, formou-se uma imagem estereotipada do sorriso que leva à sua padronização e, consequentemente, ao aumento na demanda dos pacientes por tratamentos que tornem seus sorrisos mais estéticos e agradáveis. A harmonia e simetria do sorriso consiste não apenas pela forma, posição e cor dos dentes, mas também pela face, lábios e tecido gengival (Oliveira et al., 2013; Silva et al., 2021).

Os lábios definem a zona estética do sorriso, logo, sua curvatura e comprimento podem atuar na quantidade de dentes que será exposta durante o repouso e nos movimentos funcionais. O traçado de uma linha imaginária feita pela borda inferior do lábio superior distendida pelo sorriso define a linha do sorriso. Desta forma, de acordo com o quanto de estrutura dentária vertical que vai ser visível ao sorrir, a linha do sorriso é classificada em três grupos: baixa, média e alta (Tjan, Miller, \& The, 1984)

A linha do sorriso baixa representa um sorriso que mostra menos de $75 \%$ dos dentes superiores anteriores; a linha do sorriso média configura um sorriso que mostra de $75 \%$ a $100 \%$ dos dentes superiores anteriores e as papilas interdentárias; e a linha do sorriso alta corresponde ao sorriso que mostra toda a extensão coronária dos dentes superiores anteriores e uma faixa contínua de gengiva (Tjan et al., 1984). Van Der Geld, Oosterveld, Schols e Kuijpers-Jagtman (2011) consideraram ainda um quarto grupo, em que linha do sorriso expõe uma faixa de gengiva maior que $4 \mathrm{~mm}$, classificando-o como sorriso gengival.

O "sorriso gengival" é o termo utilizado para se referir a anomalia de desenvolvimento, na qual se caracteriza pela exposição gengival exagerada quando o paciente sorri, resultando em um sorriso não estético (Braga et al., 2015).

Muitos fatores podem dar origem ao sorriso gengival, como alterações esqueléticas, dentárias, labiais, periodontais ou externas. Essa condição pode surgir como resultado de um fator etiológico ou pela combinação de vários deles (Bidra, Agar, \& Parel, 2012). Portanto, é essencial que o cirurgião-dentista conheça suas etiologias para proceder em um diagnóstico diferencial correto, que o leve a realizar uma conduta clínica pertinente a cada caso distinto (Robbins, 1999). O presente trabalho se propôs em explorar o conceito, etiologia, classificação e diagnóstico, do sorriso gengival descritas, através de uma revisão de literatura.

\section{Metodologia}

Para o presente estudo de revisão de literatura realizou-se uma pesquisa explanatório-descritiva em que foram realizadas buscas nas bases de dados Scientific Eletronic Library Online (SciELO), Biblioteca Virtual em Saúde (BVS), US 
National library of Medicine National Institutes of Health (PubMed), Google Acadêmico, bem como artigos em bases de dados de instituições de ensino superior no Brasil, e revistas científicas. Foram selecionados artigos na língua portuguesa e inglesa que foram publicados entre os anos de 1997 a 2021. Tendo como critérios de busca os seguintes descritores: sorriso; sorriso gengival; exposição gengival excessiva.

\section{Revisão de Literatura}

Um sorriso harmônico é composto pela união de três elementos: os dentes, a gengiva e os lábios. Quando esses componentes se encontram na proporção correta, o sorriso se torna esteticamente agradável. A exposição do tecido gengival exagerada, causa um desequilíbrio nessa proporção e, consequentemente, forma uma condição não estética qualificada como sorriso gengival, que pode afetar psicologicamente os pacientes. A periodontia exerce um papel importante na construção desse sorriso harmônico, porque para a grande maioria das pessoas o fato de ter elementos dentários hígidos, com uma boa coloração, acaba se tornando irrelevante para a definição do sorriso harmônico, quando se tem um sorriso gengival (Pedron, 2016; Silva et al., 2021).

O sorriso gengival é uma alteração estética comum, caracterizada pela exposição excessiva do tecido gengival anterossuperior durante o sorriso, resultado de uma relação inadequada entre a borda inferior do lábio superior e a margem gengival dos dentes anterossuperiores (Alpiste-Illueca, 2011; Oliveira et al., 2013). Já em casos mais graves, esta condição também poderá ser visualizada mesmo quando o lábio estiver em repouso (Silberberg, Goldstein, \& Smidt, 2009)

Embora o sorriso gengival possa ser originado por inúmeras causas, é comum que sua etiologia seja de natureza mista, proveniente de mais de um fator. A razão do sorriso gengival pode estar ligada a uma erupção dentária anormal, por uma hiperatividade do lábio superior, devido ao crescimento vertical excessivo da maxila, extrusão dento-alveolar ou pelo aumento do volume gengival causado pelo biofilme dentário (Silberberg et al., 2009).

Conceitua-se como erupção dentária o movimento que o dente faz do seu local de desenvolvimento (no osso) para sua posição na cavidade oral (Marks \& Schroeder, 1996). A mesma é composta por duas fases: $1^{\circ}$ ) Erupção ativa; $2^{\circ}$ ) Erupção passiva. Durante a fase de erupção ativa, o dente emerge em direção oclusal, até que ele atinja o plano oclusal com seu dente antagonista, dando fim a esta fase. Esta movimentação dentária atua no tecido gengival, que se desloca verticalmente junto a coroa dentária. Já a fase de erupção passiva é iniciada no momento em que o dente entra em contato com o seu antagonista, quando o tecido gengival localizado na junção dento-gengival (JDG) começa a migrar apicalmente até o nível da junção cemento-esmalte (JCE) (Alpiste-Illueca, 2011; Cairo et al., 2012). A erupção passiva é dividida em 4 etapas, conforme o epitélio juncional (EJ) se localiza em relação a JCE. No estágio 1, os dentes entraram em oclusão e o EJ está localizado totalmente no esmalte dental; no estágio 2, o EJ repousa parcialmente no esmalte e parcialmente no cemento da superfície radicular; no estágio 3, todo EJ se encontra no cemento, com a margem gengival localizada na JCE; e no estágio 4, o EJ e a margem gengival estão posicionados apicalmente em relação a JCE (Figura 1). Apenas o primeiro estágio é considerado um processo fisiológico, enquanto os demais são resultado de uma inflamação crônica que causa uma destruição periodontal por um processo patológico (Alpiste-Illueca, 2011). 
Figura 1. Estágios da erupção passiva. Esquema A: Estágio 1 em que os dentes entraram em oclusão e o EJ localiza-se totalmente no esmalte dentário. Esquema B: Estágio 2 onde o EJ encontra-se entre o esmalte dentário e o cemento radicular. Esquema C: Estágio 3 onde todo o EJ encontra-se no cemento e a margem gengival na JCE. Esquema D: Estágio 4 em que o EJ e a margem gengival estão posicionadas apicalmente em relação a JCE.
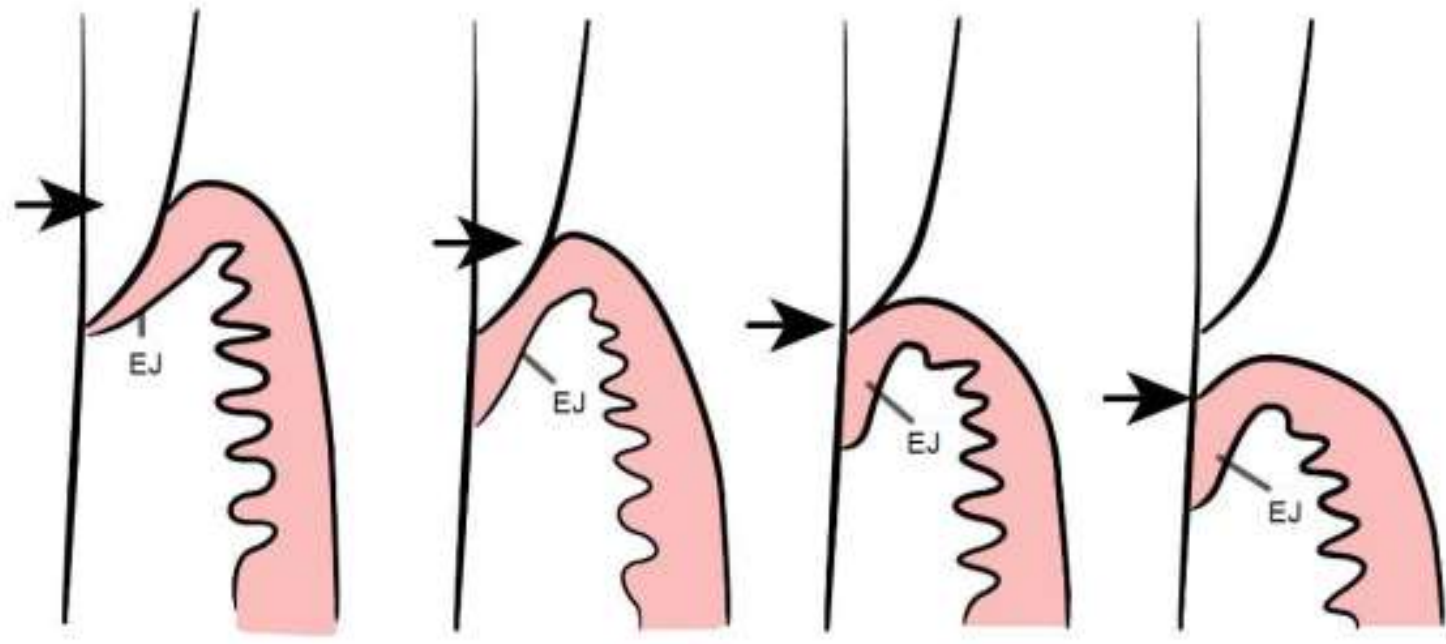

Fonte: Autoria própria.

A falha durante a fase de erupção passiva gera uma situação clínica caracterizada pela sobreposição de tecido gengival recobrindo a superfície do esmalte, provocando nas coroas dentárias uma aparência clínica curta, denominada de erupção passiva alterada (EPA) ou erupção passiva tardia (Alpiste-Illueca, 2011). Essa condição pode acometer um ou múltiplos dentes (Silberberg et al., 2009). A EPA foi classificada por Coslet, Vanarsdall, e Weisgold (1977) em dois tipos (I e II), segundo a localização do EJ em relação a crista óssea alveolar; e em dois subtipos (A e B), que descrevem a posição da crista óssea alveolar em relação a JCE (Figura 2).

Figura 2. Classificação da EPA de acordo com Coslet et al. (1977). Tipo 1A: Gengiva mais espessa da margem gengival até a linha mucogengival, com a distância entre a crista alveolar e a JCE adequados; Tipo 1B: Gengiva mais espessa da margem gengival até a linha mucogengival, com a crista alveolar no nível da JCE; Tipo 2A: dimensão gengival e distância entre a crista alveolar e a JCE adequados; e Tipo 2B: dimensão gengival adequada, com a crista alveolar no nível da JCE.

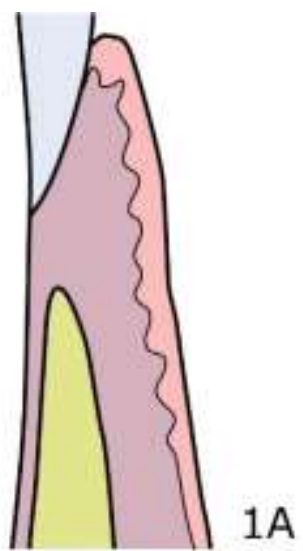

$1 \mathrm{~A}$
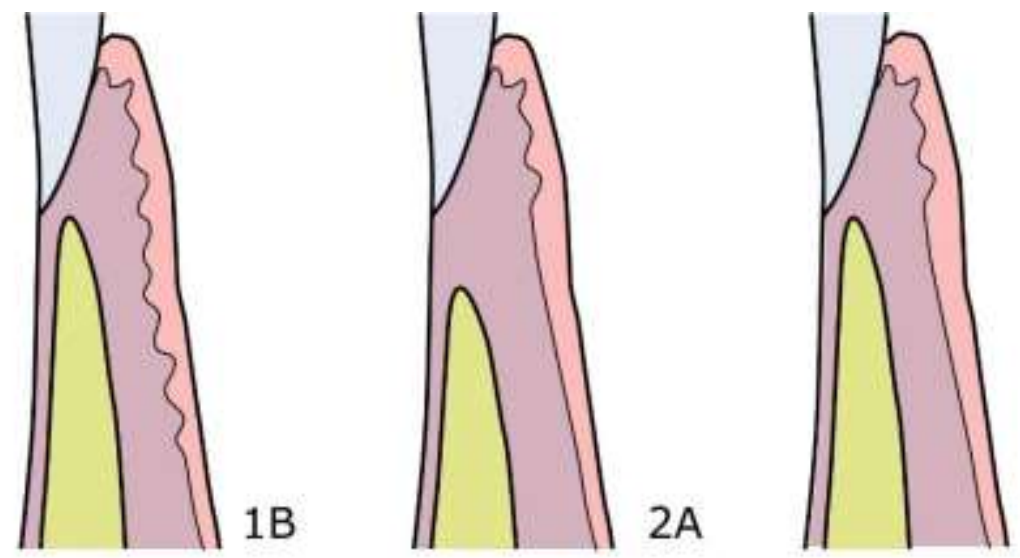

Fonte: Autoria própria. 
No tipo I, há uma volumosa quantidade de gengiva quando é medida a partir da gengiva marginal livre até a linha muco-gengival. No tipo II, a dimensão de gengiva está dentro da normalidade quando medida da gengiva marginal livre até a linha muco-gengival. No subtipo A, o espaço entre a crista alveolar e a JCE é de, aproximadamente, 1,5 mm, o que propicia a inserção das fibras gengivais na superfície do cemento. No subtipo B, a crista alveolar fica no nível da JCE, não existindo o espaço suficiente para a formação do espaço biológico (Rossi, Brunelli, Piras, \& Pilloni, 2014).

A EPA acomete 120 a cada 1000 indivíduos, a American Academy of Periodontology reconhece o excesso gengival como uma deformidade mucogengival e embora alguns autores discutam sobre o risco para a saúde periodontal que ela possa causar, sua maior implicação clínica refere-se ao desconforto estético, devido à exibição de uma quantidade excessiva de tecido gengival nos dentes anterossuperiores no ato de sorrir (Cairo et al., 2012; Galdino et al., 2021).

Para um correto diagnóstico, três fatores devem ser avaliados: a quantidade estimada de gengiva em excesso; sinais clínicos da EPA; e a idade do paciente, de modo que possamos afirmar que houve falha ao concluir o processo eruptivo. É importante que o profissional também analise as individualidades de cada paciente, como o seu tipo facial, altura vertical da face, assim como sua simetria, linha do sorriso, espessura e tamanho dos lábios, fenótipo gengival, espessura do osso alveolar e anatomia dentária, para um planejamento adequado do caso e um resultado satisfatório (Alpiste-Illueca, 2011; Waldrop, 2008; Galdino et al., 2021).

Estima-se que a erupção passiva nos dentes anteriores ocorra durante o início da adolescência e que nos dentes posteriores só finalize no final da adolescência. Após esse período, a fase de erupção passiva é considerada como inativa/alterada (Alpiste-Illueca, 2011; Waldrop, 2008).

Já a hiperatividade do lábio superior ou lábio curto é influenciada pela movimentação do lábio superior durante o sorriso e consequentemente da contração dos músculos da face que estão envolvidos na dinâmica do sorriso (elevadores do lábio superior, zigomático maior, zigomático menor e risório) e, portanto, deve ser um importante aspecto considerado na avaliação dos tecidos moles, como pode ser visualizado através da Figura 3 (Seixas, Costa-Pinto, \& Araújo, 2011; Mazzuco \& Hexsel, 2010). Se um paciente apresenta altura facial, nível da margem gengival, comprimento do lábio e altura dos incisivos centrais superiores dentro do normal e, ainda assim, possui exposição gengival excessiva, uma provável etiologia é a hiperatividade do lábio superior (Robbins, 1999).

Figura 3. Músculos responsáveis pela exposição gengival: Elevador do lábio superior e da asa do nariz (LLSAN); Elevador do lábio superior (LLS); Zigomático menor (ZMi); Zigomático maior (ZM) e Risório (Ri)

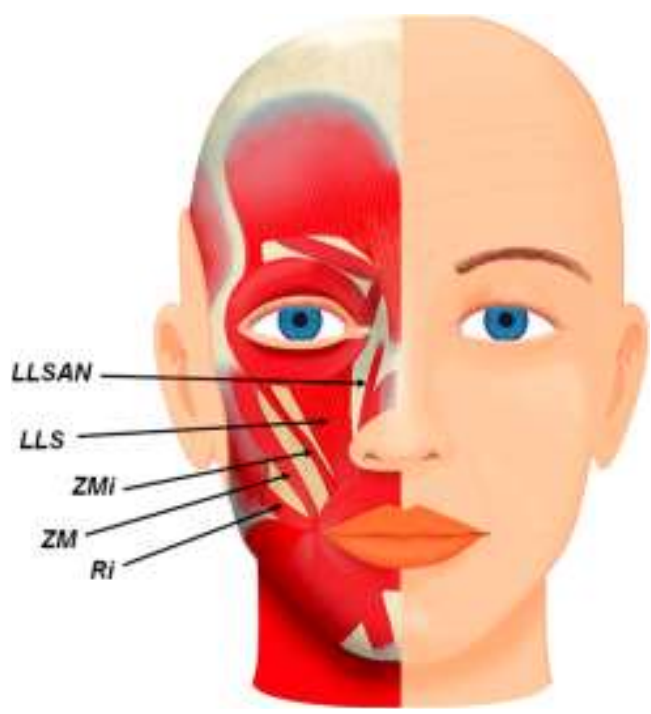

Fonte: Autoria própria. 
Os indivíduos acometidos pelo sorriso gengival têm a capacidade muscular, aproximadamente, 20\% superior de elevar o lábio superior durante o sorriso (Peck, Peck, \& Kataja, 1992). Segundo Robbins (1999), 3-4 mm dos incisivos centrais superiores são exibidos em repouso, enquanto que ao sorrir, toda coroa é exposta (10-11 mm); logo, o lábio superior se desloca 6-8 $\mathrm{mm}$ do repouso para um sorriso completo, mas em um paciente com hiperatividade do lábio superior, essa distância pode ser 1,5 a 2 vezes maior. A maior parte dos autores afirma que o músculo elevador do lábio superior e da asa do nariz seja o mais atuante para a formação do sorriso gengival. Porém, todos os músculos citados acima são responsáveis em elevar o lábio superior e possuem uma função na exibição de dentes e gengiva no sorriso (Mazzuco \& Hexsel, 2010).

Um crescimento vertical maxilar excessivo também pode estar associado ao sorriso gengival. Ao se verificar no exame clínico, paciente que dispõe do comprimento do lábio superior e mobilidade normais, entretanto portador do sorriso gengival e com exposição excessiva dos incisivos superiores em repouso, uma possível causa pode ser atribuída ao crescimento excesso vertical de maxila. Essa etiologia resulta na presença de um sorriso gengival esquelético, que é, na maioria das vezes associado à altura do terço inferior da face aumentada (Sabri, 2005).

O crescimento vertical exagerado da maxila é um "sobrecrescimento" da maxila verticalmente, geralmente causado por uma displasia esquelética que provoca um crescimento hiperplásico da base óssea maxilar (Robbins, 1999; Chu, Karabin \& Mistry, 2004). Sthapak, Kataria, Chandrashekar, Mishra, e Tripathi (2015) classificaram essa condição em três tipos diferentes de excesso de crescimento vertical, conforme descrito no Quadro 1.

Quadro 1. Classificação do excesso de crescimento vertical.

\begin{tabular}{|c|c|}
\hline Tipo I & $\begin{array}{c}\text { Excesso de crescimento vertical } \\
\text { De } 2 \text { a } 4 \mathbf{m m}\end{array}$ \\
\hline Tipo II & Excesso de crescimento vertical \\
& De 4 a $8 \mathrm{~mm}$ \\
\hline Tipo III & Excesso de crescimento vertical \\
& Maior que $8 \mathrm{~mm}$ \\
\hline
\end{tabular}

Fonte: Sthapak et al. (2015).

É indispensável verificar se o sorriso gengival não é provocado pela combinação entre o excesso vertical da maxila e a EPA. Quando associada essas etiologias, faz-se necessário tratar primeiramente a EPA, e posteriormente definir o nível de excesso vertical maxilar, avaliando o quanto restou de exposição gengival (Garber \& Salama, 1996). O diagnóstico é feito através do exame extra-oral, sendo o terço inferior da face maior que os outros dois terços, e pode ser confirmado com uma análise cefalométrica da radiografia cefalométrica (Mazzuco \& Hexsel, 2010).

A extrusão dento-alveolar também pode ser encontrada nos pacientes portadores de sorriso gengival. A mesma ocorre quando um ou mais dentes anterossuperiores sobre-erupcionam. Conforme os incisivos superiores erupcionam, o osso alveolar e o tecido gengival que o recobre acompanham o movimento dentário, o que pode gerar uma exposição gengival excessiva.

Nos pacientes que não têm a estética do sorriso comprometida, se traçarmos uma linha imaginária na margem gengival do canino superior direito até o esquerdo, essa linha deve passar também na margem gengival dos incisivos centrais superiores. Se o paciente tiver extrusão dento-alveolar dos dentes anteriores, essa linha torna-se côncava devido ao declínio da margem gengival dos incisivos centrais superiores (Robbins, 1999). Essa condição surge, geralmente, devido à falta de uma oclusão adequada, e ocorre mais comumente em pacientes com maloclusão de Classe II de Angle (Robbins, 1999). Nos casos 
em que apenas os incisivos centrais superiores são extruídos e os dentes posteriores permanecem nas suas posições verticais normais, uma mordida profunda pode surgir como consequência (Kim, Kim, \& Lee, 2006)

Já o sorriso gengival induzido pela placa bacteriana pode ser visto em pacientes com deficiência na higiene oral. Sabese que placa bacteriana é o principal fator etiológico causador de alterações nos tecidos periodontais, em razão da resposta inflamatória do hospedeiro. Este processo inflamatório na gengiva pode ser visto clinicamente como uma inflamação superficial da gengiva, em que apesar das alterações patológicas, o epitélio encontra-se íntegro, sem haver perda de inserção e sem perda óssea, sendo denominada de gengivite (Mishra, Khan, \& Mishra, 2012). A gengivite induzida por placa bacteriana pode ainda ser modificada por fatores locais, como aparelhos fixos; ou sistêmicos, como a puberdade, ciclo menstrual e diabetes (Waldrop, 2008).

Para esse tipo de paciente, deve ser dada uma instrução de higiene oral, realizado todo o exame clínico periodontal, bem como a terapêutica básica de raspagem e alisamento radicular e profilaxia dentária para controle da inflamação e estabilização do tecido gengival. Quando reestabelecida a saúde do periodonto, um diagnóstico mais preciso pode ser elaborado; o edema gengival pode ser diferenciado da hiperplasia gengival permanente e da EPA mais facilmente (Waldrop, 2008).

Para classificar os indivíduos como portadores de sorriso gengival diversos parâmetros na literatura para definir o sorriso gengival segundo a quantidade em milímetros de exposição gengival, alguns autores sugeriram um valor que o padronizasse; Garber e Salama, (1996) e diversos outros autores consideraram que a exposição deve ser maior que $3 \mathrm{~mm}$ para classificar um sorriso como sorriso gengival.

Chacón Martínez et al. (2011) propôs uma classificação do sorriso gengival, graduando-o em 3 níveis, de acordo com a severidade da exposição gengival. O grau I (leve), tem exposição gengival de 2 a 4 mm; no grau II (moderado), 4 a 6 mm do tecido gengival está exposto; e no grau III (grave), a exposição é maior que $6 \mathrm{~mm}$.

Um correto diagnóstico, requer exame dos tecidos moles e ósseo da face, seguidos por uma avaliação intraoral dos dentes/ tecido gengival, bem como sua relação com os lábios (Panossian \& Block, 2010). Para um exame completo é necessário a avaliação dos seguintes parâmetros: exame facial, em que avalie o comprimento da face, o comprimento do lábio superior, a exposição dentária em repouso e a elevação do lábio superior durante o sorriso; além de um exame intraoral, com a finalidade de mensurar a harmonia das arcadas dentárias, a proporção altura/ largura dos incisivos centrais superiores e uma avaliação periodontal (Silberberg et al., 2009).

Realizar todos os exames, avaliando todos os parâmetros citados, permite ao clínico obter um diagnóstico preciso, permitindo que o mesmo realize um plano de tratamento adequado, é essencial para que a melhor forma de tratamento seja instituída e atinja que resultados mais satisfatórios para o paciente.

\section{Discussão}

Este presente trabalho tem o objetivo de abordar a etiologia, classificação e diagnóstico do sorriso gengival, visto que é uma temática que vem sendo abordada nos últimos para obtenção de um sorriso mais estético e considerado agradável, sendo essencial para o cirurgião-dentista o conhecimento deste para obter êxito na conduta clínica de caso.

A exposição gengival excessiva se caracteriza como uma condição clínica que denominamos de sorriso gengival. A quantidade de tecido gengival exposta para classificar um sorriso como sorriso gengival diverge entre diversos autores. Liébart et al. (2004) conceituam que a exposição gengival para tal condição dever ser acima de $2 \mathrm{~mm}$, Pedron (2016) afirma que a exposição deve ser superior a $3 \mathrm{~mm}$ e Van der Geld et al. (2011) maior que $4 \mathrm{~mm}$, não existindo ainda uma unanimidade de escolha em relação ao parâmetro utilizado considerado ideal. 
Visto esse conceito, pode-se diferenciar dois termos frequentemente utilizados de forma incorreta: sorriso gengival e sorriso alto. Pacientes que apresentam um sorriso gengival possuem a linha do sorriso alta, porém o inverso não se aplica obrigatoriamente, dado que o sorriso gengival traduz uma exposição gengival superior a 3 mm (Braga et al., 2015).

Dentre os fatores etiológicos que podem dar origem ao sorriso gengival os mesmos podem ser divididos em fatores: dental (extrusão dentoalveolar), gengival (EPA e hiperplasia gengival), ósseo (crescimento vertical maxilar excessivo) ou muscular (hiperatividade muscular e lábio superior curto). A causa pode aparecer isoladamente ou múltipla (Oliveira et al., 2013).

A terapia que será selecionada para o tratamento vai variar de acordo com a(s) etiologia(s) presente(s). Quando o paciente possui etiologia multifatorial, um tratamento multidisciplinar pode ser indicado (Oliveira et al., 2013).

\section{Considerações Finais}

A grande disseminação das redes sociais nos últimos anos trouxe consigo um aumento na busca pelo padrão de beleza estabelecido pelas mídias. Homens e mulheres procuram por novos hábitos e tratamentos que visem uma melhor aparência do corpo, cabelos, pele, face e também por um sorriso harmonioso. Nessas circunstâncias, a odontologia se insere como uma ferramenta fundamental na busca pelo belo.

O equilíbrio para uma estética adequada do sorriso envolve três elementos fundamentais, que são os dentes, gengiva e lábios. Uma maior exposição da gengiva, gera um desequilíbrio entre esses componentes e dá origem a condição clínica denominada de sorriso gengival. O sorriso gengival afeta não só a estética, mas também influencia a autoestima e as relações pessoais.

Dessa forma, o cirurgião-dentista deve estar apto a identificar as causas, definindo o fator etiológico predominante em cada paciente. Um correto diagnóstico é essencial para traçar um bom plano de tratamento e oferecer ao paciente um tratamento individualizado, com resultados satisfatórios a longo prazo e que atendam a suas expectativas estéticas e funcionais.

Faz-se necessário a realização de mais pesquisas sobre diagnóstico para que haja uma sistematização e padronização das avaliações, indicando também uma padronização de tratamento proposto para correção do sorriso gengival, visando maior facilidade de diagnóstico e melhor comunicação entre os profissionais, a fim de que a eficácia no manejo dos pacientes possa ser aprimorada gerando uma maior satisfação e qualidade de vida.

\section{Referências}

Alpiste-Illueca F. (2011). Altered passive eruption (APE): a little-known clinical situation. Medicina oral, patologia oral y cirugia bucal, 16(1), e100-e104. https://doi.org/10.4317/medoral.16.e100

Bidra, A. S., Agar, J. R., \& Parel, S. M. (2012). Management of patients with excessive gingival display for maxillary complete arch fixed implant-supported prostheses. The Journal of prosthetic dentistry, 108(5), 324-331. https://doi.org/10.1016/S0022-3913(12)60186-3

Braga, M.S., Nascimento, J.M.Q., Camargo, E.B., Filho, J.M.D.C.V., Falcão, E.P., Zuza, E.P., \& Pires, J.R. (2015). Cirurgia plástica periodontal para correção de erupção passiva alterada. Braz J Periodontol, 24(4), 64-68.

Cairo, F., Graziani, F., Franchi, L., Defraia, E., \& Pini Prato, G. P. (2012). Periodontal plastic surgery to improve aesthetics in patients with altered passive eruption/gummy smile: a case series study. International journal of dentistry, 2012, 837658. https://doi.org/10.1155/2012/837658

Chacón Martínez, H., Castro Govea, Y., Pérez Porras, S., Vázquez Costilla, O., González Cárdenas, H.R., \& Mendoza Adam, G.. (2011). Simplificando el tratamiento quirúrgico de la sonrisa gingival. Cirugía Plástica Ibero-Latinoamericana, 37(1), 43-49.

http://scielo.isciii.es/scielo.php?script=sci_arttext\&pid=S0376-78922011000100005\&lng=es\&tlng=es

Chu, S. J., Karabin, S., \& Mistry, S. (2004). Short tooth syndrome: diagnosis, etiology, and treatment management. Journal of the California Dental Association, 32(2), 143-152.

Coslet, J. G., Vanarsdall, R., \& Weisgold, A. (1977). Diagnosis and classification of delayed passive eruption of the dentogingival junction in the adult. The Alpha omegan, 70(3), 24-28. 
Darakh, P., Khadtare, Y., Waghmare, P., Mali, A. (2017). Treatment of altered passive eruption by surgical gingivectomy: A case report. IP Int J Periodontol Implantol, ;2(2), 64-68.

Galdino, D. A., de Macedo Bernardino, Í., do Nascimento Barbosa, D., Ferreira, I. J., da Silva, F. A., da Silva, B. D., \& Costa, L. G. C. (2021). Correção do sorriso gengival através do aumento de coroa clínica usando a técnica flapless: Uma revisão integrativa. Research, Society and Development, 10(5), e10210512753-e10210512753.

Garber, D. A., \& Salama, M. A. (1996). The aesthetic smile: diagnosis and treatment. Periodontology 2000, 11, 18-28. https://doi.org/10.1111/j.16000757.1996.tb00179.x

Kim, T. W., Kim, H., \& Lee, S. J. (2006). Correction of deep overbite and gummy smile by using a mini-implant with a segmented wire in a growing Class II Division 2 patient. American journal of orthodontics and dentofacial orthopedics : official publication of the American Association of Orthodontists, its constituent societies, and the American Board of Orthodontics, 130(5), 676-685. https://doi.org/10.1016/j.ajodo.2005.07.013

Liébart, M.F., Fouque-Deruelle, C., Santini, A., Dillier, F.L., Monnet-Corti, V., Glise, J.M., \& Borghetti, A. (2004). Smile line and periodontium visibility. Periodont Pract today, 1,17-25.

Marks, S. C., Jr, \& Schroeder, H. E. (1996). Tooth eruption: theories and facts. The Anatomical record, 245(2), 374-393. https://doi.org/10.1002/(SICI)10970185(199606)245:2<374::AID-AR18>3.0.CO;2-M

Mazzuco, R., \& Hexsel, D. (2010). Gummy smile and botulinum toxin: a new approach based on the gingival exposure area. Journal of the American Academy of Dermatology, 63(6), 1042-1051. https://doi.org/10.1016/j.jaad.2010.02.053

Mishra, M. B., Khan, Z. Y., \& Mishra, S. (2011). Gingival overgrowth and drug association: a review. Indian journal of medical sciences, 65(2), 73-82. https://doi.org/10.4103/0019-5359.103971

Oliveira, M. T., Molina, G. O., Furtado, A., Ghizoni, J. S., \& Pereira, J. R. (2013). Gummy smile: A contemporary and multidisciplinary overview. Dental Hypotheses, 4(2), 55.

Panossian, A. J., \& Block, M. S. (2010). Evaluation of the smile: facial and dental considerations. Journal of oral and maxillofacial surgery : official journal of the American Association of Oral and Maxillofacial Surgeons, 68(3), 547-554. https://doi.org/10.1016/j.joms.2009.09.021

Peck, S., Peck, L., \& Kataja, M. (1992). The gingival smile line. The Angle orthodontist,62(2), 91-102. https://doi.org/10.1043/00033219(1992)062<0091:TGSL >2.0.CO;2

Pedron, I. G. (2016). Harmonização da estética dentogengivofacial. Clín. int. j. braz. dent, 150-155.

Robbins J. W. (1999). Differential diagnosis and treatment of excess gingival display. Practical periodontics and aesthetic dentistry : PPAD, 11(2), 265-273.

Rossi, R., Brunelli, G., Piras, V., \& Pilloni, A. (2014). Altered passive eruption and familial trait: a preliminary investigation. International journal of dentistry, 2014, 874092. https://doi.org/10.1155/2014/874092.

Sabri R. (2005). The eight components of a balanced smile. Journal of clinical orthodontics : JCO, 39(3), 155-154.

Seixas, M. R., Costa-Pinto, R. A., \& Araújo, T. M. D. (2011). Checklist of aesthetic features to consider in diagnosing and treating excessive gingival display (gummy smile). Dental Press Journal of Orthodontics, 16, 131-157.

Silberberg, N., Goldstein, M., \& Smidt, A. (2009). Excessive gingival display--etiology, diagnosis, and treatment modalities. Quintessence international (Berlin, Germany : 1985), 40(10), 809-818.

Silva, H. F. V., Leite, R. B., de Oliveira, M. S. G., Leite, J. V. C., de Oliveira Felismino, C. M., de Araujo Cruz, M. E., Santos, A., Gusmão, G.P., \& Lima, L. N. C. (2021). Avaliação de diferentes técnicas para correção do sorriso gengival: Revisão da literatura. Research, Society and Development, 10(5), e54510515092-e54510515092.

Sthapak, U., Kataria, S., Chandrashekar, K. T., Mishra, R., \& Tripathi, V. D. (2015). Management of excessive gingival display: Lip repositioning technique. Journal of the International Clinical Dental Research Organization, 7(2), 151.

Tjan, A. H., Miller, G. D., \& The, J. G. (1984). Some esthetic factors in a smile. The Journal of prosthetic dentistry, 51(1), 24-28. https://doi.org/10.1016/s0022-3913(84)80097-9.

Van der Geld, P., Oosterveld, P., Schols, J., \& Kuijpers-Jagtman, A. M. (2011). Smile line assessment comparing quantitative measurement and visual estimation. American journal of orthodontics and dentofacial orthopedics : official publication of the American Association of Orthodontists, its constituent societies, and the American Board of Orthodontics, 139(2), 174-180. https://doi.org/10.1016/j.ajodo.2009.09.021.

Waldrop, T. C. (2008, December). Gummy smiles: the challenge of gingival excess: prevalence and guidelines for clinical management. In Seminars in orthodontics,14(4), 260-271. 